\title{
Effectiveness of safety-based incentives in Public Private Partnerships: Evidence from the case of Spain
}

\author{
Thais Rangel , José Manuel Vassallo ，Blanca Arenas
}

\begin{abstract}
Many countries around the world are implementing Public-Private-Partnership (PPP) contacts to manage road infrastructure. In some of these contracts the public sector introduces economic incentives to the private operator to foster the accomplishment of social goals. One of the incentives that have been introduced in some PPP contracts is related to safety in such a way that the better the safety outcome the greater will be the economic reward to the contractor. The aim of this paper is at identify whether the incentives to improve road safety in highway PPPs are ultimately effective in improving safety ratios. To this end Poisson and negative binomial regression models have been applied using information from highway sections in Spain. The findings indicate that even though road safety is highly influenced by variables that are not much controllable by the contractor such as the Average Annual Daily Traffic and the percentage of heavy vehicles, the implementation of safety incentives in PPPs has a positive influence in the reduction of fatalities, injuries and accidents.
\end{abstract}

\section{Introduction}

Many countries around the world are seeking new means to involve the private sector in managing and financing infrastructure through Public Private Partnerships (PPPs). Three reasons lay behind this trend: the growing budgetary constraints, the search for greater productivity efficiency, and the improvement of quality through a better allocation of risks and incentives (OECD, 2008). One of the most common ways of implementing PPPs in managing infrastructure is through the concession approach, which consists basically in transferring final design, construction, maintenance, and operation of the infrastructure to a private consortium, in exchange for the right to charge a fee to the user or to the government on behalf of the user, for a period of time contractually agreed in advance (Vassallo and Gallego, 2005).

Concession contracts should include the necessary provisions in order that the relationship between the public and the private sector work at their best throughout the life of the contract. To this end, the bidding terms and contracts should comply with two requirements: first, ensuring that the most efficient bidder in terms of price and quality will be granted the contract; and second, providing incentives to the contractor to render the highest quality level compatible with a reasonable cost. 
One of the key aspects of PPPs is precisely to encourage the private sector to manage and operate the infrastructure in the best way. To this end, in recent years, PPPs have been evolving from mere demand-based contracts to service-based contracts that refer to different aspects such as availability, congestion, state of the pavement, safety, and so on. Consequently, the revenues for the contractor tend to depend more and more on performance-based standards rather than on traffic demand (Harding et al., 2010).

Two reasons lie behind this trend. First, PPP contractors can manage better the service performance they offer than the ultimate traffic flows on the infrastructure. And second, by encouraging the PPP contractors to provide a better service, by aligning the social with the private benefits, they will end up producing a more efficient outcome for society.

The aim of this paper is to identify whether incentives to improve road safety in PPPs, by controlling other variables that may influence road safety, are ultimately effective at improving safety ratios. We propose a methodology, to analyze the effect of safety incentives on road safety in highway PPPs. The results showed that there are more fatalities, injuries and accidents on road segments without incentives when they are compared with other segments with incentives.

Apart from the introduction, the paper contains six additional sections. In Section 2, right after the introduction, we describe the practical experience in the introduction of safety incentives in highway PPPs. In Section 3, we give a literature review of the models explaining the variables influencing road safety ratios. In Section 4, we define the methodology we have implemented in this research and the data sources used for the empirical analysis. In Section 5, we show the main results of the model together with our comments. In the sixth and last section, we list our main conclusions and approach further research.

\section{Road Public Private Partnerships in Spain}

Spain turns out to be a good example for this research because both public and private highways coexist in the network. The highway capacity network has been developed on the basis of either public highways or private highways-most of them toll concessions-depending on the government in office.

The first interurban highways in Spain were developed on the basis of toll concessions funded solely by the private sector. Between 1967 and 1975, the Spanish government granted $2042 \mathrm{~km}$ of toll highway concessions. The results of the implementation of concession contracts in Spain during this period were rather controversial. On the one hand, toll highway concessions achieved the goal of providing the country with a modern highway network at a time when the public budget of Spain was not sufficient to afford such a huge cost. On the other hand, the guarantees made by the government to concession funding over time became very costly for the country (Izquierdo and Vassallo, 2004).

From 1976 to 2005 no highway concession was awarded in Spain. There were several reasons for this. First, the two oil crises in the 1970s destabilized the Spanish economy. Second, after Franco's death, the political atmosphere in Spain was uncertain. Third, and most important, the Socialist government, which took office in 1982 and remained until 1996, was politically opposed to promoting private concessions as a means of financing highways.

The socialist government continued expanding the highway network by building free highways on the basis of conventional public procurement. These free publicly built highways were called in Spain autovías. This term has been used in Spain since then on as a means to label free highways and distinguish them from toll highways (autopistas). The autovias are built, funded and managed by the Spanish government. None of the public highways (autovias) have economic incentives to improve road safety though the government is committed to building and maintaining them according to the standard procedures approved by the Ministry of Public Works.

The first autovias in Spain were built by doubling lanes out of single carriageways. The characteristics of these highways (known as first generation autovias) have alignment standards below those of toll highways. From 2000, the alignment standards of new autovías were improved notably to make them comparable with toll highways. These are called second generation autovias. This is the reason why we distinguish first generation autovias from second generation autovias in the road operation RO variable.

Consequently, we distinguished toll highways and second generation autovías, which have similar alignment design standards from first generation autovías.

In 1996, the conservative People's Party took office in Spain. The need to contain Spain's public deficit was the most difficult challenge facing the new government. This was the main reason why the new government decided to implement once again the policy of offering concessions to encourage the participation of the private sector in financing new transportation infrastructures. From 1996 until the time of writing, $1003 \mathrm{~km}$ of new toll highways concessions have been awarded by the central government of Spain through this approach

From 1996 to the present, the government has promoted both free public highways (autovias) and toll highway concessions. Toll highway concessions are usually implemented in richer regions of the country where the possibility of raising revenue to make the business viable for the public sector is greater.

\section{Safety-based incentives in Public Private Partnerships}

The revenues obtained by private contractors managing PPP contracts have been traditionally linked to the level of traffic rather than to performance-based requirements. However, in the last few years most PPP contracts have been used to promote and introduce incentives tied to bonuses and penalties to foster the contractor to provide the optimal quality levels in 
terms of several factors such as availability, state of the pavement, safety, etc. Some countries, such as the United Kingdom, have mostly replaced the demand-based approach (Debande, 2002) by the performance-based approach. Other countries, such as Spain, have incorporated bonuses and penalties tied to performance-based standards in many of their PPP contracts (Delgado et al., 2007).

These performance-based incentives, however, have to be introduced in the right way in PPP contracts. To that end, the marginal reward to the contractor for reaching a certain quality level should never be larger than the marginal social benefit produced at that level. The contractor should provide a quality level at the point where the marginal revenue obtained due to a certain quality increase equals to its marginal cost. If the incentives are defined this way, the contractor will be encouraged to provide the best service compatible with its production costs (Vassallo, 2007).

Europe is the world region with the greatest tradition in incorporating performance-based incentives in PPPs. Spain, Finland, Hungary, Norway, Portugal and the United Kingdom have introduced positive incentives based on explicit road safety indicators. Positive incentives mean that the contractor will be rewarded if it performs above the standards required. Italy introduced price-caps tied to road safety indicators in such a way that the concessionaire is allowed to set higher tolls if the safety ratios become better. In Ireland, PPP road contracts include some road safety indicators but they do not provide bonuses. In other countries, like Denmark, the Netherlands and Belgium, new and sophisticated PPP contracts have been implemented, but they do not have positive incentives based on explicit road safety indicators.

The design of the road safety indicators is quite heterogeneous across different PPP programs. There are differences both in the variables adopted to measure the outcome, in the way to set the threshold beyond which the contractor will be rewarded or penalized, and in the economic incentives used to reward and penalize the contractor. To measure the outcome, most of the PPPs use the number of injuries, number of fatalities or a combination of the number of light accidents, serious accidents and fatal accidents.

Including the exposure to the risk, expressed by traffic, is a generalized practice. In fact, only the first British shadow toll roads contracts did not introduce traffic. The rest of the contracts we have had access to take into account traffic by dividing the initial accident data by the annual traffic in terms of billion vehicles-kilometers. E18 road (Muurla-Lohja) in Finland, M6 road in Hungary, several PPPs in Portugal (the IP-4, for instance) and the latest PPP roads awarded in Spain use this methodology.

The benchmark to determine bonuses and penalties in highway PPP contracts is usually established in terms of the performance of similar highways. These similar highways are usually characterized in terms of the annual average daily traffic. If the safety indicator of the highway PPP evaluated is above a certain percentile of comparable highways the contractor will have the right to be rewarded and vice versa. The aim of this approach is to control the general evolution of casualties by many factors, most of which are not manageable by the road operator. There are many examples of the implementation of this approach: E-18 road (Grimstad - Kristiansand) in Norway, the latest PPP roads awarded in the United Kingdom (for example, A1 and M25) and some PPP roads in Spain (like the M-407 highway).

Regarding the method of rewarding or penalizing the contractor, we have basically identified two trends: incentives related to the extension of the contract period of the project, and incentives related to increase of the toll or fee to be paid to the PPP contractor.

\section{Models that identify variables influencing road safety: a literature review}

In order to establish a methodology to evaluate the impact that safety-based incentives have in the final safety outcomes, we need to know the models used to identify variables influencing road safety. In this section we explore the latest trends in road safety modeling and determine the main variables influencing road safety.

\subsection{Accident prediction models}

Although the ordinary least square regression model (OLS) is applied in the road safety literature (Zlatopher, 1988; Hakim et al., 1991), some other authors have questioned its suitability (Jovanis and Chang, 1986; Miaou et al., 1992; Miaou and Lum, 1993). This method assumes that the dependent variable is continuous and normally distributed with a constant variance. This technique lacks the distributional property necessary to describe adequately random, discrete and nonnegative events such as traffic accidents. The statistical results derived from these OLS models are therefore questionable. One concern in using multiple linear regressions is that the number of traffic accidents may not have a normal distribution but instead follow a Poisson distribution. The relationships using the Poisson distribution have been developed by means of the technique of Generalized Linear Models (GLMs).

Although the Poisson regression represents a significance advance in modeling accidents, this method has the assumption that the variance of a Poisson distribution is equals to its mean. However, the variance of traffic accidents are often larger than the mean. The negative binomial (NB) model is an extension of the Poisson model to overcome possible overdispersion in the data (Miaou and Lum, 1993; Noland and Oh, 2004; Chang, 2005; Caliendo et al., 2007; Arenas et al., 2009).

\subsection{Dependent and independent variables}

Accident frequency (number of accidents per year) and accident rates (number of accidents per million vehicle-kilometres) are the most appropriate dependent variable for predictive models. 
Many independent variables affect crashes such as traffic flow, section length, weather, geometric characteristics, speed limits and human behavior. Researchers generally extract a reduced number of variables for inclusion in the proposed model.

From an empirical stand-point, the relationship between accident frequency and traffic flows can be found in Abdel-Aty and Essam Radwan (2000), Persaud et al. (2000) and Anastasopoulos and Mannering (2009); and the relationship between accident rate and traffic flow can be found in Vitaliano and Held (1991), Hauer and Bamfo (1997) and Hadi et al. (1995). The relationship between accident frequency or accident rate and traffic flow show a great variation in their results.

Abdel-Aty and Essam Radwan (2000), Persaud et al. (2000) and Anastasopoulos and Mannering (2009), point out that accident frequency increases with AADT. On the other hand, Vitaliano and Held (1991) cannot detect any significant increase in the accident rate when AADT increases. According to Martin (2002) and Hauer and Bamfo (1997) the accident rate even decreases with an increasing AADT. Hadi et al. (1995) proposed several accident prediction models. The results show that accident rates increase with increasing AADT on roads having higher levels of traffic, while it decreases with AADT on roads with lower traffic volumes.

Few authors have analyzed the effect of heterogeneous flows, and specifically the effect that the presence of heavy good vehicles (HGVs) in the traffic flow has on accidents. Hiselius (2004) analyzed the relationship between accident frequency and traffic flow in four different road types according to speed limit and road width in two conditions: homogenous and heterogeneous traffic. The results show that the expected number of accidents increases less than proportionally with the traffic flow, in the homogenous case. For the heterogeneous case, the expected number of accidents decreases with increasing number of trucks. According to Arenas et al. (2009), the expected number of accident increases with the addition of one vehicle in AADT (maintaining HGV constant), and increases with one additional HGV (maintaining AADT constant) when comparing high capacity roads to single carriageway roads.

Other studies have been carried out in recent years to establish relationships between accidents and traffic characteristics and the frequency of intersections (Ivan and O'Mara, 1997), with environmental factor (Chang, 2005; Keay and Sommonds, 2006; Caliendo et al., 2007), with geometric infrastructure characteristics (Hauer, 2004; Chang, 2005), with number of lanes (Milton and Mannering, 1998; Noland and Oh, 2004; Chang, 2005), and with speed limits (Ossiander and Cummings, 2002; Wong et al., 2005).

\subsection{Research gaps and contributions}

There is an abundant literature on road accident prediction models to investigate the effects that various variables may have on road safety. However, there are no references that simultaneously address the relationship between road safety and incentives given to the concessionaires or road safety and infrastructure management. As a result, there is at least one main reason for justifying this paper which is motivated by the need to quantify safety incentives on road safety in highway PPPs.

The aim of this paper is to identify whether incentives to improve road safety in PPPs are ultimately effective to improve safety ratios. In this paper we applied Poisson and NB regression models to determine the relationship between road safety and a set of exogenous variables related to traffic flow, infrastructure management and characteristics of infrastructure which are explained in the next section.

\section{Methodology}

Since accident occurrences are discrete, non-negative and random events, the Poisson and NB regression models appear to be appropriate models. Besides, the statistical models most commonly used to explain the relationship between motor vehicle accidents and a set of predictor variables are the Poisson and NB regression models, as previously discussed in Section 4.1.

The Poisson distribution represents a significant advance at describing traffic accident data. However, it contains certain weaknesses. It assumes that the variance of the dependent variable is equal to its mean but in practice the variance of the traffic accident data tend to be larger than the mean. This extra variation is known as overdispersion and, if it is present, the estimated coefficients may be inefficient and the standard error is biased. The overdispersion does not affect the values of the model parameters, but can affect the Wald statistics or likelihood statistics for testing the hypothesis about the parameters. Thus, in order to take this into account, the more indicated model is the negative binomial regression (NB) which enables the variance of the dependent variable to differ from its mean.

Both approaches (Poisson and NB regression models) have been widely used to analyze count data where the dependent variable is discrete and defined for non-negative integers corresponding to the number of events occurring in a given interval. However, NB regression is preferred if overdispersion is observed, as is common in traffic accident data.

In this paper Poisson and NB are applied to determine the relationship between three endogenous variables: fatalities, injuries and accidents; and a set of exogenous variables. These variables are related to traffic flow such as: (1) Average Annual Daily Traffic (AADT) and (2) percentage of heavy good vehicles (\%HGV), infrastructure management and characteristics of infrastructure such as (3) road operation (RO), which reflects the way the highway is ultimately managed, (4) incentives (INC), which evaluates whether the private contractors have incentives or not to improve the safety if the highways are managed by them, and (5) number of lanes in each stretch (LANES).

This paper focuses on the evaluation of the effect of variables related to the infrastructure management: RO and INC on road safety. As far as the authors are aware, there are no previous works closely related to this approach. 


\subsection{Data}

The models we calibrated in this research are based on data from year 2006. In 2006, there were $12,075 \mathrm{~km}$ of high-capacity highways in Spain (Ministry of Public Works, 2006a). The population for the models is made up of road stretches from the Spanish high-capacity network, with an average length of road stretch being $7 \mathrm{~km}$.

\subsubsection{Road operation}

The road operation ( $\mathrm{RO}$ ) variable corresponds to the operational differences of the highway network in Spain.

The RO variable in the model is a categorical variable that takes a different value if the highway stretch is located in a toll highway (TH) concession, a first generation autovía (1AV), or a second generation autovía (AV). Toll highways are PPPs, while AV and $1 \mathrm{AV}$ are public highways.

The main difference between these types of roads is that the private sector is responsible for the maintenance of toll highways while the public sector is responsible for the maintenance of autovías (1AV and AV). Another difference between these two groups is that the legislation prohibits mopeds, tractors and bicycles from entering toll highways and second generation autovías.

1AV have alignment standards below those of toll highways and AV. As mentioned before in Section 2, the alignment standards of new autovías (AV) were improved notably to make them comparable with toll highways. TH and AV have similar alignment standards.

Data for RO was obtained from information provided by the Ministry of Public Works and from a research done by Sánchez et al. (2006).

\subsubsection{Incentives}

The main reason offering incentives to contractors is to achieve government objectives such as an efficient traffic management, increase project demand, decrease accident rate, overall improve road conditions and so on.

Most of the toll highway concessions implemented in the last few years in Spain include performance-based incentives consisting of contractual provisions to extend the contract duration up to four years if several performance-based indicators tied to quality aspects like queuing in toll plazas, congestion, state of the pavement, safety, and satisfaction of the users are ultimately fulfilled.

Regarding safety, the PPP contractor can be granted an extension of the contract if safety indicators remain below an accident benchmark for similar highways. For this purpose the government measures on a yearly basis the Risk Index (RI) and Mortality Index (MI) of the highways and compare it with other highways with similar characteristics in terms of alignment and traffic flow.

To know which segments had road safety incentives (INC) we analyzed each concession contract in force in 2006 . The first Spanish concession contract awarded with implementation of road safety incentives was in 2002 . We analyzed all of the contracts from 2002 to 2006.

INC is a dummy variable, which indicates the presence or not of incentives to improve safety in each stretch.

\subsubsection{Other variables}

For modeling, we selected exogenous variables that may potentially influence safety and do not depend on the concessionaire's ability to manage the road. The objective was to know the relationship between incentives given to the concessionaire and road safety controlled by the variables that the concessionaire cannot manage. These are: continuous variables such as (1) Average Annual Daily Traffic (AADT), (2) percentage of heavy goods vehicles (\%HGV) and (3) number of lanes for each stretch (LANES) plus the two selected variables that may explain any relation between PPPs and accidents, (4) road operation (RO) and (5) incentives (INC).

Furthermore, as offset of the models we choose the vehicle exposure (vk), measured in millions of vehicle-kilometers as $\mathrm{vk}_{\mathrm{j}}=365 l_{\mathrm{j}} \mathrm{AADT}_{\mathrm{j}} / 10^{6}$, where $\mathrm{AADT}_{\mathrm{j}}$ and $l_{\mathrm{j}}$ are respectively the Average Annual Daily Traffic and length (km) of road section $\mathrm{j}$ obtained from a traffic database. The vk variable was considered because accident counts are strongly influenced by exposure levels. Vehicle exposure estimates the potential probability for a crash occurring (Qin et al., 2004).

The response variables are number of fatalities, injuries and accidents. These data came from the police-reported accident data supplied by the Ministry of Internal Affairs (2006). The traffic data was supplied by the Ministry of Public Works (2006b). The final database combines both accident and traffic data from these two different sources.

Traffic flow (AADT) is counted as the number of vehicles through a fixed section in both directions. Portable counting instrument and permanent inductive loops were used to count the number of vehicles. \%HGV was calculated from HGV and AADT, and LANES was calculated using the number of lanes and the length of each stretch. LANES is the mean weighted by length.

\subsubsection{Selection of stretches}

A total of 1042 road segments were extracted out of 6293 from the 2006 traffic map. The sample was made up of interurban road stretches of the Spanish high capacity network both PPP highways (toll highways) and public highways (autovías). 
Table 1

Road segment data.

\begin{tabular}{|c|c|c|c|c|c|c|c|}
\hline \multirow[t]{3}{*}{ Road operation } & \multicolumn{6}{|l|}{ Segments } & \multirow[t]{3}{*}{ length $(\mathrm{km})$} \\
\hline & \multicolumn{3}{|l|}{ No } & \multicolumn{3}{|l|}{$\%$} & \\
\hline & With accidents & Without accidents & Total & With accidents & Without accidents & Total & \\
\hline AV & 275 & 287 & 562 & 26.39 & 27.54 & 53.93 & 3790.46 \\
\hline $1 \mathrm{AV}$ & 43 & 266 & 309 & 4.13 & 25.53 & 29.66 & 2285.02 \\
\hline $\mathrm{TH}$ & 60 & 111 & 171 & 5.76 & 10.65 & 16.41 & 1372.24 \\
\hline Total & 378 & 664 & 1042 & 36.28 & 63.72 & 100 & 7447.72 \\
\hline
\end{tabular}

Table 2

Descriptive statistics of endogenous variables by road operation and total. Year 2006.

\begin{tabular}{|c|c|c|c|c|c|c|c|}
\hline Variables & Road operation & Mean & S.D. & Range & Minimum & Maximum & Sum \\
\hline \multirow[t]{4}{*}{ Fatalities } & AV & 0.18 & 0.62 & 6 & 0 & 6 & 102 \\
\hline & $1 \mathrm{AV}$ & 0.16 & 0.75 & 9 & 0 & 9 & 48 \\
\hline & $\mathrm{TH}$ & 0.14 & 0.52 & 4 & 0 & 4 & 24 \\
\hline & Total & 0.17 & 0.65 & 9 & 0 & 9 & 174 \\
\hline \multirow[t]{4}{*}{ Injuries } & $\mathrm{AV}$ & 4.43 & 9.48 & 97 & 0 & 97 & 2488 \\
\hline & $1 \mathrm{AV}$ & 6.31 & 26.33 & 250 & 0 & 250 & 1951 \\
\hline & $\mathrm{TH}$ & 3.38 & 10.21 & 102 & 0 & 102 & 578 \\
\hline & Total & 4.81 & 16.48 & 250 & 0 & 250 & 5017 \\
\hline \multirow[t]{4}{*}{ Accidents } & AV & 2.51 & 5.30 & 50 & 0 & 50 & 1413 \\
\hline & $1 \mathrm{AV}$ & 3.63 & 15.24 & 145 & 0 & 145 & 1121 \\
\hline & $\mathrm{TH}$ & 1.90 & 4.92 & 36 & 0 & 36 & 325 \\
\hline & Total & 2.74 & 9.39 & 145 & 0 & 145 & 2859 \\
\hline
\end{tabular}

We excluded urban segments and segments without complete information for traffic flow and infrastructure variables. We considered stretches with and without accidents to avoid selection bias. The study includes PPPs (toll highways) and public highways (first and second generation autovias). The final data base represents $62 \%$ of the total Spanish high-capacity network. The total number of segments (with and without accidents) and the length by road operation are presented in Table 1 . And $63.72 \%$ of the total segments had no accidents.

The descriptive statistics of endogenous variables by road operation are presented in Table 2 . The mean of injuries and accidents is higher for $1 \mathrm{AV}$ than AV and TH. As we explained before $1 \mathrm{AV}$ roads have design standards below AV and TH. However, the mean of fatalities is higher in AV than $1 \mathrm{AV}$ and TH.

The descriptive statistics of exogenous variables by road operation, displayed in Table 3 , indicate that the mean traffic intensity (AADT) is higher on $1 \mathrm{AV}$ than $\mathrm{AV}$ and TH. The low traffic intensity in TH could be explained because the users pay tolls. There is more heavy goods vehicle traffic on public highways (AV and 1AV) than PPPs (TH). The range and the standard deviation in $\mathrm{AV}$ and $1 \mathrm{AV}$ are higher than $\mathrm{TH}$, which indicates more heterogeneity in traffic flow.

The first descriptive statistics for the traffic variables AADT and \%HGV indicated the need to use the logarithm transformation to expand low values and contract high values. The logarithmic transformation is used to stabilize the variance of a sample. The measures of central tendency take similar values through logarithm transformation. The natural logarithms of the explanatory variables (except for LANES) were used to minimize heteroskedasticity. After transformation, the range values (maximum and minimum) of AADT and\%HGV variables were greatly reduced. The standard deviation is very low compared with the mean; therefore, the distribution was further improved. The logarithmic transformation is shown in Appendix. However, the chi square goodness of fit test rejects the null hypothesis that the variables follow a normal distribution.

\section{Modeling results}

The Poisson overdispersion parameter indicates that the data may be overdispersed. When Pearson's chi-square divided by the degrees of freedom is greater than 1 , the data may be overdispersed, otherwise the data may be underdispersed. Therefore, it was necessary to test the NB as an alternative model, which enables the variance of the dependent variable to differ from its mean.

After testing several models, we ended up adopting the one that we show in this section.

The general equation in a segment $j$, road operation $\left(\mathrm{RO}_{\mathrm{ij}}=\frac{1}{3}\right)$ being $\mathrm{RO}_{3 \mathrm{j}}=\mathrm{AV}$ the reference class, and the incentives systems to the concessionaire $\left(\mathrm{INC}_{\mathrm{lj}}=\frac{1-y e s}{0=n o}\right)$ is:

$$
\hat{E}\left[Y_{\mathrm{ij}}\right]=\exp \left[\hat{\beta}_{0}+\hat{\beta}_{1} \log \left(\mathrm{AADT}_{\mathrm{ij}}\right)+\hat{\beta}_{2} \log \left(\% \mathrm{HGV}_{\mathrm{ij}}\right)+\hat{\beta}_{3}\left(\mathrm{LANES}_{\mathrm{ij}}\right)+\hat{\alpha}_{\mathrm{i}}\left(\mathrm{RO}_{\mathrm{ij}}\right)+\hat{\kappa}_{1}\left(\mathrm{INC}_{\mathrm{lj}}\right)+\log \left(\mathrm{vk}_{\mathrm{ij}}\right)\right]
$$


Table 3

Descriptive statistics of exogenous variables by road operation and total. Year 2006.

\begin{tabular}{|c|c|c|c|c|c|c|}
\hline Variables & Road operation & Mean & S.D. & Range & Minimum & Maximum \\
\hline \multirow[t]{4}{*}{ AADT } & AV & 23,686 & 21,876 & 139,040 & 1270 & 140,310 \\
\hline & $1 \mathrm{AV}$ & 35,735 & 34,262 & 186,370 & 5135 & 191,500 \\
\hline & $\mathrm{TH}$ & 16,508 & 12,950 & 58,093 & 1094 & 59,187 \\
\hline & Total & 26,081 & 26,046 & 190,406 & 1094 & 191,500 \\
\hline \multirow[t]{4}{*}{$\% \mathrm{HGV}$} & AV & 18.53 & 10.12 & 72.40 & 2.80 & 75.20 \\
\hline & $1 \mathrm{AV}$ & 23.37 & 8.95 & 48.10 & 4.60 & 52.70 \\
\hline & $\mathrm{TH}$ & 10.35 & 5.39 & 32.60 & 1.50 & 34.10 \\
\hline & Total & 18.63 & 10.08 & 73.70 & 1.50 & 75.20 \\
\hline \multirow[t]{4}{*}{ LANES } & AV & 4.16 & 0.87 & 6.00 & 2.00 & 8.00 \\
\hline & $1 \mathrm{AV}$ & 4.30 & 0.73 & 5.00 & 3.00 & 8.00 \\
\hline & $\mathrm{TH}$ & 4.29 & 0.85 & 6.00 & 2.00 & 8.00 \\
\hline & Total & 4.22 & 0.83 & 6.00 & 2.00 & 8.00 \\
\hline \multirow[t]{4}{*}{ vk } & AV & 52.28 & 56.22 & 450.65 & 1.05 & 451.70 \\
\hline & $1 \mathrm{AV}$ & 79.25 & 70.65 & 355.89 & 3.13 & 359.02 \\
\hline & $\mathrm{TH}$ & 42.51 & 42.91 & 248.92 & 1.75 & 250.67 \\
\hline & Total & 58.67 & 60.60 & 450.65 & 1.05 & 451.70 \\
\hline
\end{tabular}

Table 4

Negative binomial regression models for fatalitites, injuries and accidents.

\begin{tabular}{|c|c|c|c|c|c|}
\hline Variables & Measurement level & & Fatalities & Injuries & Accidents \\
\hline Intercept & & & $3.622^{c}(5.413)$ & $0.874(1.755)$ & $-0.180(0.063)$ \\
\hline $\log (A A D T)$ & $\mathrm{S}$ & & $-0.972^{\mathrm{a}}(49.535)$ & $-0.276^{\mathrm{a}}(21.386)$ & $-0.223^{a}(11.893)$ \\
\hline $\log (\% \mathrm{HGV})$ & $\mathrm{S}$ & & $-0.030(0.028)$ & $-0.438^{\mathrm{a}}(32.701)$ & $-0.478^{a}(33.046)$ \\
\hline \multirow[t]{2}{*}{ INC } & C & Stretch with incentives & $-1.152(1.093)$ & $-0.792^{d}(3.684)$ & $-1.041^{\mathrm{c}}(4.220)$ \\
\hline & & Stretch without incentives & 0 & 0 & 0 \\
\hline LANES & $S$ & & $0.104(1.339)$ & $0.145^{\mathrm{b}}(8.534)$ & $0.166^{\mathrm{b}}(9.721)$ \\
\hline \multirow[t]{3}{*}{ Road operation } & C & $\mathrm{TH}$ & $-0.300(1.213)$ & $-0.376^{b}(10.476)$ & $-0.358^{\mathrm{b}}(7.835)$ \\
\hline & & $1 \mathrm{AV}$ & $-0.244(1.313)$ & $-0.318^{a}(13.566)$ & $-0.370^{a}(15.776)$ \\
\hline & & $\mathrm{AV}$ & 0 & 0 & 0 \\
\hline $\log (v k)$ & & S & 1 & 1 & 1 \\
\hline Deviance $\left(D^{\mathrm{p}}\right)$ & & & 516,269 & 2389.771 & 1798.057 \\
\hline Pearson Chi-Square $\left(\mathrm{X}^{2}\right)$ & & & 1472.585 & 4013.498 & 2722.568 \\
\hline Log likelihood & & & -430.021 & -2274.830 & -1822.464 \\
\hline AIC & & & 874.043 & 4563.660 & 3658.928 \\
\hline $\mathrm{BIC}$ & & & 908.685 & 4598.303 & 3693.571 \\
\hline Overdispersion parameter $(k)$ & & & 1.423 & 3.878 & 2.631 \\
\hline
\end{tabular}

Measure level: scale (S), categorical (C).

${ }^{a} p<0.001$.

b $p<0.01$.

c $p<0.05$.

d $p<0.10$.

where: $\hat{E}\left[Y_{\mathrm{ij}}\right]$ is the expected number of fatalities, injuries or accidents; $\mathrm{AADT}_{\mathrm{ij}}$ is the Annual Average Daily Traffic; \% $\mathrm{HGV}_{\mathrm{ij}}$ is the percentage of heavy goods vehicles; LANES $_{\mathrm{ij}}$ is the number of lanes in each stretch; $R O_{\mathrm{ij}}$ is road operation which could be toll highway (TH), first generation autovía (1AV) and second generation autovía (AV); $I_{N C_{1 j}}$ reflects the introduction of road safety incentives in the stretch analyzed. This is a dummy variable, it takes 1 when the contract has safety incentives and it takes 0 when the contract does not have safety incentives; $v_{\mathrm{ij}}$ is the vehicle exposure measured in million of vehiclekilometers.

Table 4 summarizes the estimated NB regressions. Each column refers to a model for each response variables (fatalities, injuries and accidents), while every row display the estimated parameters for the exogenous variables of the model. The significance of coefficients was checked using Wald statistic (in brackets), which rejects the null hypothesis that the coefficient is zero with a level of $95 \%$ confidence. Different goodness-of-fit statistics were used to select the model such as deviance, loglikelihood and Pearson chi-square statistics. Other measures were also evaluated such as Akaike Information Criterion (AIC) (Akaike, 1974) and the Bayesian Information Criterion (BIC) (Schwarz, 1978).

A criterion for variables inclusion was used by testing the likelihood ratio (LR). In addition, the correlation coefficient between them was prevented. Looking in detail at Table 4, we can highlight the following results, ceteris paribus:

1. $\log (A A D T)$ is the most significant predictor variable for the fatality, injury and accident rates. The coefficient signs are negative for all models (fatalities, injuries and accidents), suggesting that a greater AADT is associated with lower rates for fatalities, injuries and accidents (ceteris paribus). 

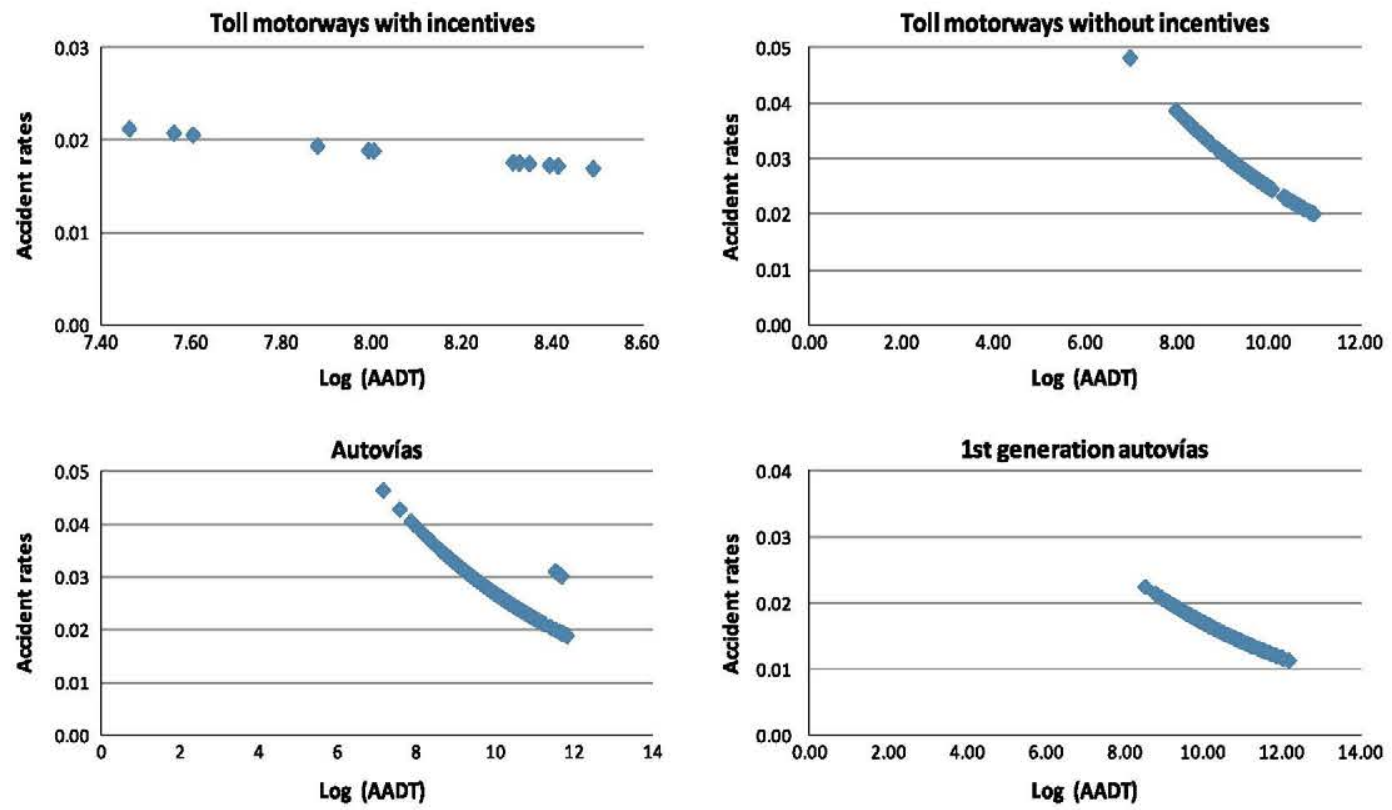

Fig. 1. Accident rates in relation to AADT.

This result is also analyzed visually. Fig. 1 present the accident rates in relation to AADT, while maintaining \%HGV constant. Data presented in Fig. 1 indicates that the accident rates decreasing with an increasing of AADT on TM (with and without incentives), AV and AV. This result confirms the hypothesis proposed by Vitaliano and Held (1991) and Hauer and Bamfo (1997) that accident rates decrease when AADT increases.

2. Log (\%HGV) was found to be statistically significant for injury and accident models. The coefficient signs are negative for all models. This means that the larger the percentage of heavy good vehicles (ceteris paribus) the smaller the injury and accident rates. This could be related to the speed reduction that heavy vehicles impose to light vehicles on the traffic flow. An increasing number of HGV accordingly slow down the traffic because of two reasons: the speed limit for HGVs is lower than for light cars and HGVs could force the rest of vehicles to reduce the speed to maintain the safety distance, to ensure the visibility and enable drivers to have enough reaction time in case of an unexpected maneuver.

This result is also analyzed visually in Fig. 2, which present the accident rates in relation to \%HGV, while maintaining AADT constant. The visual analysis is not in conflict with the regression analysis, the accident rates decreasing with an increasing of \% HGV on TM (with and without incentives), AV and 1AV. This result is in line with Hiselius (2004), if this analysis was in terms of number of accidents.

1. The LANES variable showed the expected positive signs in all models. This means that a larger number of lanes are associated with larger rates of fatalities, injuries and accidents (ceteris paribus). This variable was found to be statistically significant for injury and accident models. The reason for this is that in highways with more lanes the interactions between drivers is greater so the probability of crashing increases. This result is in line with the findings of Milton and Mannering (1998), Noland and Oh (2004) and Chang (2005) that the accident risk increases with the number of lanes.

2. INC variable showed the expected negative sign, suggesting that establishing incentives in the contracts is associated with lower rates for fatalities, injuries and accidents (ceteris paribus). The coefficient signs do not change throughout the three models. This variable was found to be statistically significant for injuries (with a level of $90 \%$ confidence) and accidents (with a level of $95 \%$ confidence).

3. RO indicates that there is a different behavior among toll highways, second generation autovias and first generation autovias. Toll highways (TH) showed the expected negative sign in all models suggesting that there are fewer fatalities, injuries and accidents in toll highways compared with AV (ceteris paribus), which is the reference class. In other words, toll highways managed and operated by the private sector turn out to be safer that free highways managed and operated by the public sector. The only odd result that we found in our analysis is that the variable $1 \mathrm{AV}$ has an unexpected negative sign suggesting that $1 \mathrm{AV}$ has fewer fatalities, injuries and accidents compared to AV. This result is strange because, as we mentioned earlier in this paper, first generation autovias (1AV) have poorer design standards than second generation autovías (AV). 

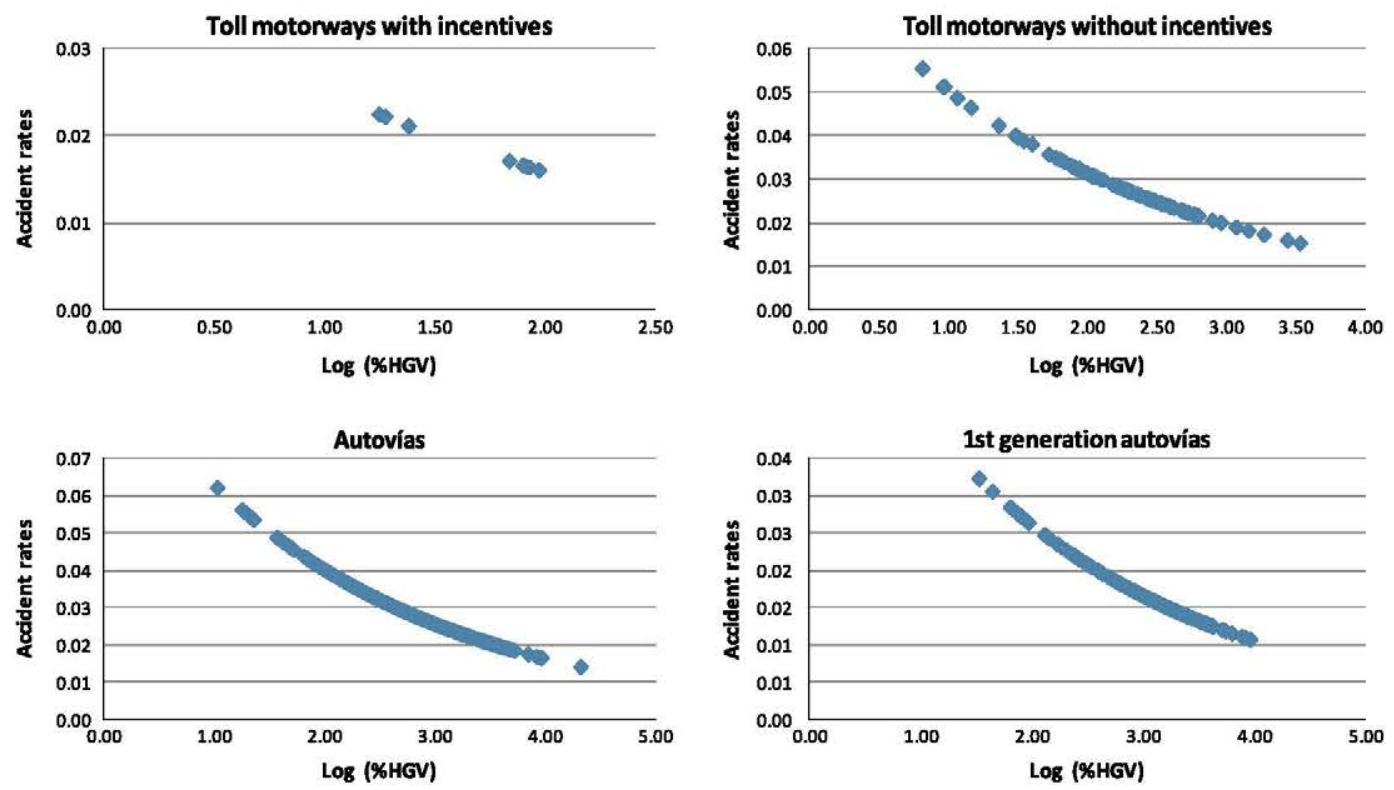

Fig. 2. Accident rates in relation to \%HGV.

The reason we found for this unexpected result is that first generation autovias are among the busiest highways in Spain in terms of traffic so the AADT in these highways is closer to their capacity and consequently the speed of the flow is lower, which improves safety ratios.

The expressions of accident rates for different road operations (RO) can be determined by the parameters estimated in Table 4. As one example, the equations of toll highways by segment $(j)$ in specific scenarios are calculated in the following way:

$$
\hat{\lambda}_{\mathrm{ij}}=\frac{E\left[\hat{Y}_{\mathrm{ij}}\right]}{\mathrm{vk}_{\mathrm{j}}}
$$

The average accident rates per million vehicle-kilometers are the following for toll highways segments with incentives:

$$
\hat{\lambda}_{\mathrm{TH}_{\mathrm{j}}}=0.243(\overline{\mathrm{AADT}})^{-0.223}(\overline{\% \mathrm{HGV}})^{-0.478}=0.009
$$

Whereas the average accident rates per million vehicle-kilometers are the following for toll highways segments without incentives:

$$
\hat{\lambda}_{\mathrm{TH}_{\mathrm{j}}}=0.690(\overline{\mathrm{AADT}})^{-0.223}(\overline{\% \mathrm{HGV}})^{-0.478}=0.026
$$

From these expressions it can be clearly observed that the incentives given to the concessionaires have a positive impact on reducing accident rates. The accident rate per 1 million vehicle-kilometers is about 2.88 times higher in toll highways without incentives compared to toll highways with incentives.

\section{Conclusions and further research}

The most important result from this research is that setting up safety-based incentives in PPPs is an effective measure to manage highways. In other words, there are more fatalities, injuries and accidents on highway segments without incentives than on highway segments with incentives. This fact demonstrates that the implementation of road safety incentives in PPP is an effective measure to encourage the contractor to handle safety in a better way.

We obtained this result because, in the case of Spain, we found that the INC variable is statistically significant for the injury and accident models. The sign of the INC variables is also negative for the fatality models but it is not significant at the $95 \%$. This result suggests that accident and injury rates are better performance-measures to incentivize private operators than fatality rates.

The safety incentives in Spain are not a substantial source of revenue for PPP contractors when compared with other countries such as Finland and United Kingdom. Even though safety incentives in Spain are small compared to other countries, the implementation of safety incentives in PPPs has had a positive influence in the reduction of fatalities, injuries and accidents. 
Table 5

Logarithm transformation of AADT,\%HGV and vk by road operation and total. Year 2006.

\begin{tabular}{|c|c|c|c|c|c|c|c|c|}
\hline \multirow{2}{*}{$\begin{array}{l}\text { Variables } \\
\text { Road operation }\end{array}$} & \multicolumn{4}{|l|}{ AADT } & \multicolumn{4}{|c|}{$\log$ (AADT) } \\
\hline & $\mathrm{AV}$ & $1 \mathrm{AV}$ & $\mathrm{TH}$ & Total & $\mathrm{AV}$ & $1 \mathrm{AV}$ & $\mathrm{TH}$ & Total \\
\hline Mean & 23,686 & 35,735 & 16,508 & 26,081 & 9.77 & 10.19 & 9.40 & 9.83 \\
\hline S.D. & 21,876 & 34,262 & 12,950 & 26,046 & 0.79 & 0.71 & 0.83 & 0.82 \\
\hline Range & 139,040 & 186,370 & 58,093 & 190,406 & 4.70 & 3.62 & 3.99 & 5.17 \\
\hline Minimum & 1270 & 5135 & 1094 & 1094 & 7.15 & 8.54 & 7.00 & 7.00 \\
\hline \multirow[t]{2}{*}{ Maximum } & 140,310 & 191,500 & 59,187 & 191,500 & 11.85 & 12.16 & 10.99 & 12.16 \\
\hline & \multicolumn{4}{|l|}{$\% \mathrm{HGV}$} & \multicolumn{4}{|c|}{$\log (\% \mathrm{HGV})$} \\
\hline Mean & 18.53 & 23.37 & 10.35 & 18.63 & 2.76 & 3.07 & 2.20 & 2.76 \\
\hline S.D. & 10.12 & 8.95 & 5.39 & 10.08 & 0.57 & 0.44 & 0.55 & 0.60 \\
\hline Range & 72.40 & 48.10 & 32.60 & 73.70 & 3.29 & 2.43 & 3.13 & 3.92 \\
\hline Minimum & 2.80 & 4.60 & 1.50 & 1.50 & 1.03 & 1.53 & 0.40 & 0.40 \\
\hline \multirow[t]{2}{*}{ Maximum } & 75.20 & 52.70 & 34.10 & 75.20 & 4.32 & 3.96 & 3.53 & 4.32 \\
\hline & \multicolumn{4}{|l|}{$\mathrm{vk}$} & \multicolumn{4}{|c|}{$\log (\mathrm{vk})$} \\
\hline Mean & 52.28 & 79.25 & 42.51 & 58.67 & 3.49 & 3.92 & 3.22 & 3.57 \\
\hline S.D. & 56.22 & 70.65 & 42.91 & 60.60 & 1.03 & 1.03 & 1.16 & 1.07 \\
\hline Range & 450.65 & 355.89 & 248.92 & 450.65 & 6.07 & 4.74 & 4.96 & 6.07 \\
\hline Minimum & 1.05 & 3.13 & 1.75 & 1.05 & 0.05 & 1.14 & 0.56 & 0.05 \\
\hline Maximum & 451.70 & 359.02 & 250.67 & 451.70 & 6.11 & 5.88 & 5.52 & 6.11 \\
\hline
\end{tabular}

This paper has paved the way for new topics that undoubtedly would require further research. First, the analysis of the size of the economic incentive set up in the PPP contract on the ultimate improvement of safety ratios is a crucial aspect. Second, a cross-cutting comparison of the different types of incentives (i.e. incentives related to the deadline of the project vs. incentives related to payments) would be of the greatest interest. Third, an analysis of the evolution of safety performance over the years in highway PPPs with safety-based incentives would shed light on the long-term effectiveness of these incentives.

\section{Appendix A}

See Table 5.

Abdel-Aty, M.A., Essam Radwan, E.A., 2000. Modeling traffic accident occurrence and involvement. Accident Analysis and Prevention 32, 633-642.

Akaike, H., 1974. A new look at the statistical model identification. IEEE Transaction on Automatic Control 19, 716-723.

Anastasopoulos, P., Mannering, F., 2009. A note on modeling vehicle accident frequencies with random-parameters count models. Accident Analysis and Prevention 41, 153-159.

Arenas, B., Aparicio, F., González, C., Gómez, A., 2009. The influence of heavy good vehicle traffic on accidents on different types of Spanish interurban roads. Accident Analysis and Prevention 41, 15-24.

Caliendo, C., Guida, M., Parisi, A., 2007. A crash-prediction model for multilane roads. Accident Analysis and Prevention 39, 657-670.

Chang, L.Y., 2005. Analysis of freeway accident frequencies: negative binomial regression versus artificial neural network. Safety Science 43, 541-557.

Debande, O., 2002. Private financing of transport infrastructure. An assessment of the UK experience. Journal of transport Economics and Policy 36, 355387.

Delgado, C., Vassallo, J.M., Sánchez, A., 2007. Aplicación de Indicadores de Calidad en concesiones de carreteras en España. Carreteras 151, 53-68.

Hadi, M.A., Aruldhas, J., Chow, L., Wattleworth, J.A., 1995. Estimating safety effects of cross-section design for various highway types using Negative Binomial regression. Transportation Research Record 1500, 169-177.

Hakim, S., Shefer, D., Hakkert, A., Hocherman, I., 1991. A critical review of macro models for road accidents. Accident Analysis and Prevention 23, 379-400.

Harding, J., Bodarwé, H., Čadež, I., 2010. Evaluation of Availability and Service Performance Based Payment Mechanisms for PPP Road Traffic Infrastructure Projects. Transportation Research Board, Washington, DC.

Hauer, E., Bamfo, J., 1997. Two tools for find what function links the dependent variable to the explanatory variables. In: Proceedings of the ICTCT Conference, lund.

Hauer, E., 2004. Safety models for Urban Four Lane Undivided Road Segments. Transportation Research Board No. 985901. TRB. Washington, DC, pp. 96105.

Hiselius, L.W., 2004. Estimating the relationship between accident frequency and homogeneous and inhomogeneous traffic flows. Accident Analysis and Prevention 36, 985-992.

Ivan, J., O'Mara, P., 1997. Prediction of traffic accident rates using Poisson regression. In: 76th Annual Meeting of the Transportation Research Board, No. 970861, TRB. Washington, DC.

Izquierdo, R., Vassallo, J.M., 2004. Nuevos sistemas de gestión y financiación de infraestructuras de transporte. Colegio de Ingenieros de Caminos, Canales y Puertos. Madrid.

Jovanis, P., Chang, H., 1986. Modeling the Relationship of Accident to Mile Travelled. Transportation Research Record, No. 1068, pp. 42-51.

Keay, K., Sommonds, I., 2006. Road accident and rainfall in a large Australian city. Accident Analysis and Prevention 38, 445-454.

Martin, J.-L., 2002. Relationship between crash rate and hourly traffic flow on interurban motorways. Accident Analysis and Prevention 34, 619-629.

Miaou, S.P., Hu, P.S., Wright, T., Rathi, A.K., Davis, S.C., 1992. Relationship Between Truck Accidents and Highway Geometry Design: A Poisson Regression Approach. Transportation Research Record, No. 1376, pp. 10-18.

Miaou, S.P., Lum, H., 1993. Modeling vehicle accidents and highway geometric design relationships. Accident Analysis and Prevention 25, 689-709.

Ministry of Public Works, 2006a. Statistical Yearbook 2006. Spain. 
Ministry of Public Works, 2006b. Traffic Map 2006. General Directorate of Roads, Spain.

Ministry of Internal Affairs, 2006. Accidents Database 2006. General Directorate of Road Traffic, Spain.

Milton, J., Mannering, F., 1998. The relationship among highway geometrics, traffic-related elements and motor vehicle accident frequencies. Transportation $25,395-413$.

Noland, R.B., Oh, L., 2004. The effect of infrastructure and demographic change on traffic-related fatalities and crashes: a case study of lllinois county-level data. Accident Analysis and Prevention 36, 525-532.

Organization for Economic Cooperation and Development, 2008. Transport Infrastructure Investment: Options for Efficiency. International Transport Forum, OECD, Paris, France.

Ossiander, E.M., Cummings, P., 2002. Freeway speed limits and traffic fatalities in Washington State. Accident Analysis and Prevention $34,13-18$.

Persaud, B., Retting, R. A., Lyon, C. (2000). Guidelines for identification of hazardous highway curves. Transportation Research Record, No. 1717, pp. 14-18.

Qin, X., Ivan, J.N., Ravishanker, N., 2004. Selecting exposure measures in crash rate prediction for two-lane highway segments. Accident Analysis and Prevention 36, 183-191.

Sánchez, A., Vassallo, J.M., Castroman, A., Delgado, C., 2006. Nuevo modelo de gestión concesional en autovías de primera generación. ETSI Caminos, Canales y Puertos. Universidad Politécnica de Madrid. Ministerio de Fomento.

Schwarz, G., 1978. Estimating the dimension of a model. The Annals of Statistics 6, 461-464.

Vassallo, J.M., Gallego, J., 2005. Risk-sharing in the New Public Works Concession Law in Spain. Transportation Research Record, No. 1932, pp. 1-8.

Vassallo, J.M., 2007. Implementation of quality criteria in tendering and regulating infrastructure management contracts. Journal of Construction Engineering and Management 133, 553-561.

Vitaliano, D.F., Held, J., 1991. Road accident external effects: an empirical assessment. Applied Economics 23, 373-378.

Wong, S.C., Sze, N.N., Lo, K.H., Hung, W.T., Loo, B.P.Y., 2005. Would relaxing speed limits aggravate safety? A case study of Hong Kong. Accident Analysis and Prevention 37, 377-388.

Zlatopher, T., 1988. Testing for functional form and autocorrelation in the analysis of motor vehicle deaths. Quarterly Review of Economics and Business 27, 6-17. 